\title{
Clinico-radiological and functional outcomes of distal tibia extra-articular fractures (AO 43A1-A3) managed by minimal invasive plate osteosynthesis in a tertiary care hospital: a series of 21 patients
}

\author{
Pankajvir Singh, Abdul Ghani, Simran Preet Singh*, Amarjeet Singh
}

Department of Orthopaedics, GMC, Jammu, Jammu and Kashmir, India

Received: 22 February 2021

Accepted: 09 March 2021

\section{*Correspondence:}

Dr. Simran Preet Singh,

E-mail: simransingh2681@gmail.com

Copyright: ( ) the author(s), publisher and licensee Medip Academy. This is an open-access article distributed under the terms of the Creative Commons Attribution Non-Commercial License, which permits unrestricted non-commercial use, distribution, and reproduction in any medium, provided the original work is properly cited.

\begin{abstract}
Background: The fractures around distal tibia are challenging injuries due to limited soft tissue coverage, precarious blood supply and subcutaneous nature of the tibia. Minimal invasive plating for distal tibia fracture is a very good option for treatment, as this does not disrupt the blood supply and cause very little insult to soft tissue.

Methods: 21 patients with extra-articular fractures of distal tibia were operated using minimally invasive plate osteosynthesis (MIPO) technique of plating. They were followed up to six months in terms of radiological union and functional outcomes, and complications. Functional outcome was assessed using Olerud Molander scoring system.

Results: Good to excellent results were obtained in almost all the patients using Olerud and Molander scoring system, mean score being 80 . These results were in comparison with the studies done earlier.

Conclusions: Our study concluded that clinico-radiological and functional outcomes of distal tibia extra-articular fracture managed by MIPO technique of plating are satisfactory with minimal complications.
\end{abstract}

Keywords: Distal tibia extra-articular, MIPO, Plating

\section{INTRODUCTION}

Fractures of the distal tibia can be challenging to treat because of the limited soft tissue, the subcutaneous bone and precarious vascularity. The aim in distal tibial fractures is to neutralize the metaphyseal fragment, realign limb length and early functional recovery. ${ }^{1}$ Distal tibial fractures account for less than $10 \%$ of the fracture of lower extremity with fibula fractured in about $85 \%$ of cases with male predominance. Fractures which are treated conservatively have been associated with malunion, shortening, restricted range of motion and early osteoarthritis. ${ }^{2,3}$ Surgical fixation is considered for most distal tibia fractures which require meticulous preoperative planning. Available options for stabilizing fractures are external fixator, interlocking nails and locking plates. ${ }^{4}$
External fixation can be a useful option in open fractures with soft tissue injury, but can lead to pin-track infections, septic arthritis, mal-alignment and delayed union. ${ }^{5}$ IMIL nailing has been reported with higher rate of malunion whereas wound infection with delayed union or non-union requiring secondary procedures like bone grafting are some of the complications associated with conventional osteosynthesis with plates. ${ }^{6-10}$

Minimally invasive sub muscular and subcutaneous plate fixation (MIPO) is a very good option as it addresses the issues associated with intramedullary nailing, preserves fracture fragment vascularity and minimizes soft tissue insult while amalgamating all biological benefits of closed reduction and fixation. 
This study aimed at assessing the clinico-radiological and functional outcomes of distal tibial extra-articular fractures using MIPO technique of plating.

\section{METHODS}

All the patients satisfying inclusion criteria who underwent MIPO for distal tibia extra-articular fractures from January 2019 to November 2020 at the Department of Orthopaedics, Government Medical College Jammu were included in the study. A written and informed consent was taken from all the patients for their inclusion in the study. Operative procedure as well as complications of the surgery and anaesthesia was explained well before hand. The collected data of all the patients included in the study design was analyzed using appropriate statistical methods. This study was an observational prospective study.

\section{Inclusion criteria}

Patients suffering from post-traumatic distal tibial extraarticular fracture, age group 20-60 years, AO type 43A1 to A3 (i.e. only extra-articular) were included in the study.

\section{Exclusion criteria}

Patients with pathological fractures, paediatric fractures (before physeal closure), severely mangled extremity, and old fractures with implant failure were excluded from the study.

A total of 23 patients were involved in the study but 2 were lost to follow up. The complete data of remaining 21 patients $(n=21)$ is being presented here.

Appropriate radiographs (AP and lateral) of the involved limb with knee and ankle were taken (Figure 1). Computed tomographic (CT) scan was done in doubtful cases to rule out intra-articular extension of fracture line.

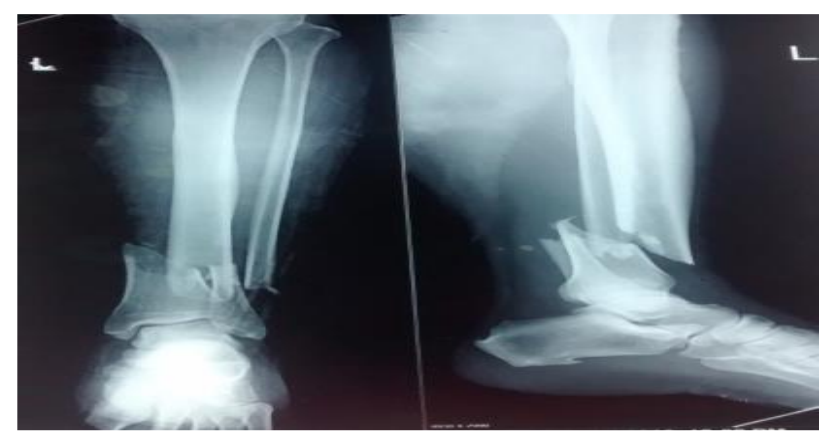

Figure 1: Radiographs showing distal tibia extra articular fracture (AO 43A2) in AP and lateral views.

All baseline blood investigation, electrocardiograph (ECG) and chest X-rays were done. The time to surgery was decided by the soft tissue condition and patient fitness. The patient was positioned supine on a radiolucent operating table under spinal or epidural anaesthesia and an anteromedial incision was given with medial malleoli as reference taking care not to injure the saphenous vein and nerve. Subcutaneous plane was made without stripping the periosteum and disturbing the fracture site. Fracture was reduced under $\mathrm{c}$ arm and precontoured plate was slided in retrograde manner beneath the skin tunnel. Plate was initially fixed with help of $\mathrm{K}$ wires (Figure 2). With separate stab incisions locking screws were used on either side of fracture site under $\mathrm{C}$ arm guidance. Reduction was confirmed under $\mathrm{C}$ arm and wound was irrigated with saline and closure done in layers. Suction drain was not used in any case. Sterile dressing was done and posterior slab was given with ankle in neutral position.

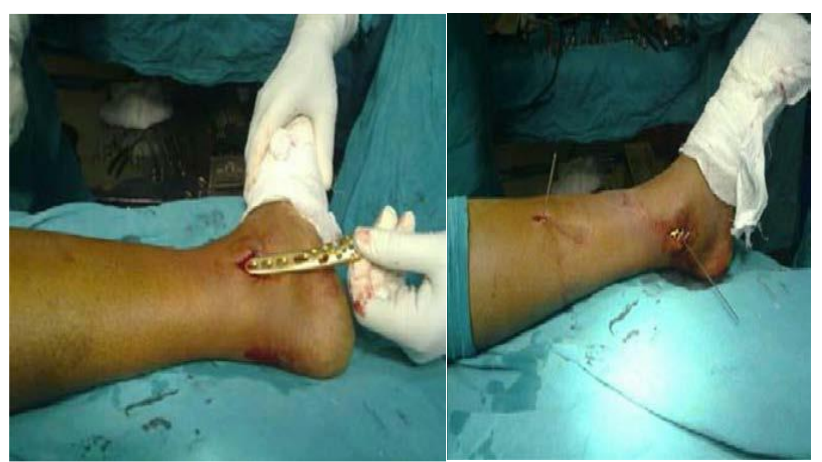

Figure 2: Picture showing plate being slided through skin tunnel and held with k-wires initially.

\section{Post-operative protocol and follow up}

Limb elevation was done postoperatively and IV antibiotics were given for 3 days followed by course of oral antibiotics. Weight bearing was restricted till radiological signs of fracture union were seen, however gentle ankle ROM was done by temporarily removing backslab. X-rays were done on 2 nd postoperative day (Figure 3). Antiseptic dressing was done on second and seventh postoperative day. Stitch removal was done at around 2 weeks postoperatively. Patients were discharged when stable and when wound was settled. Patients were followed up at 2 weeks, 6 weeks, 3 months, 6 months and then at 1 year. Healing was judged by both clinical (pain and motion at fracture site) and radiological (bridging callus at fracture site) criteria and function outcome was reviewed using Olerud and Molander scoring system.

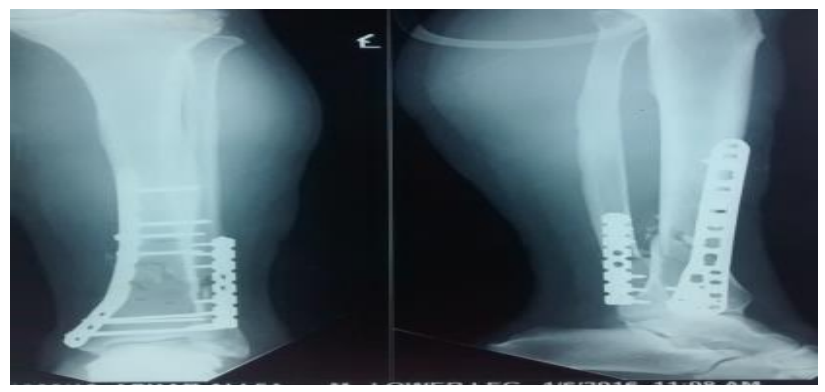

Figure 3: Immediate post-operative radiographs (fibula was fixed with a reconstruction plate). 


\section{RESULTS}

This prospective study included 21 patients $(n=21)$ out of which $15(71.4 \%)$ were male and $6(28.6 \%)$ were female with a male female ratio of $2.5: 1$. The most common age group was $40-50$ years with mean age 40.7 years. The sex and age distribution are depicted in Figure 4 and 5 respectively.

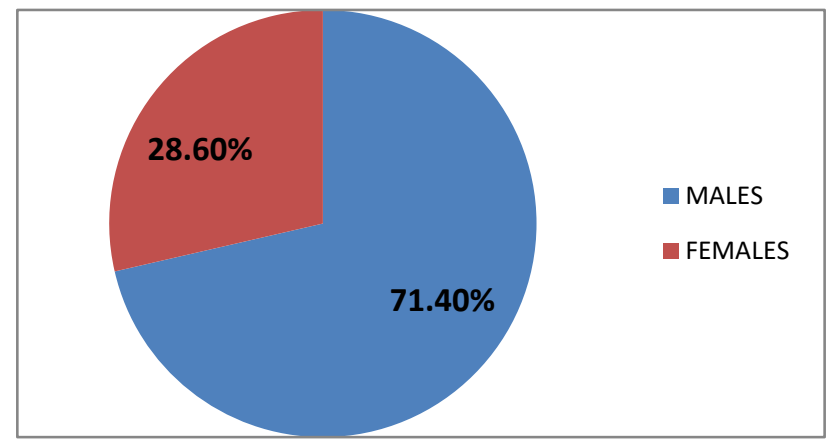

Figure 4: Sex distribution.

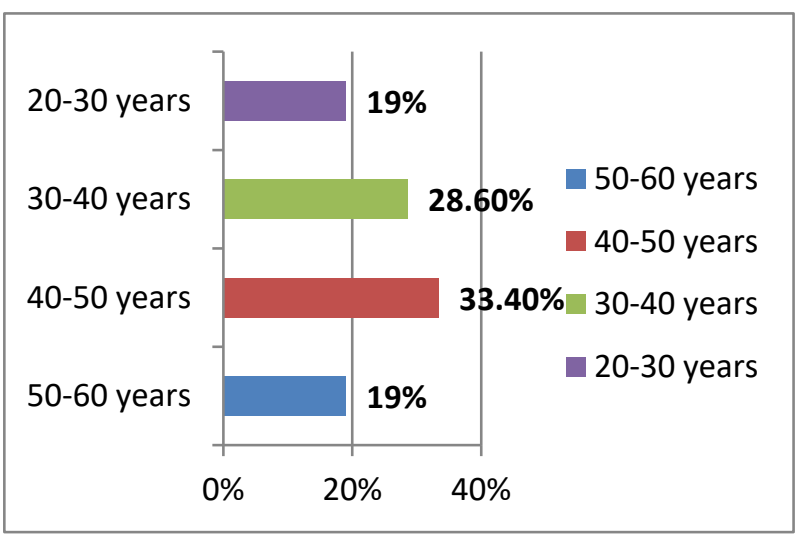

Figure 5: Distribution of patients according to age.

In present study the most common reason was high energy trauma due to injury following RTA (76.2\%, 16 patients), second most common cause was fall from stairs, tree and slip on level ground $(23.8 \%, 5$ patients). All the fractures were classified using standard AO/OTA classification. All the injuries included in our study were closed injuries with 18 patients $(85.7 \%)$ sustaining a concomitant fibula fracture and 3 patients $(14.3 \%)$ had intact fibula. The fibula was fixed with plate or intramedullary rush nail in few cases depending upon fracture anatomy. In this study, 14 patients $(66.7 \%)$ were operated in second week following admission after soft tissue healing and appearance of wrinkling sign and only 7 patients $(33.3 \%)$ got operated within a week following trauma. Characteristics of various parameters in this study design are summarized in Table 1.

Average duration for radiological union was 18.4 weeks (range 17.6-24.2 weeks). In this study there were 2 cases of malunion and 1 patient landed up in non-union (smoker patient) that required a second surgery (iliac crest bone graft). There were 2 cases of superficial wound infections, one among them was diabetic and both cases were managed with appropriate culture specific antibiotics and serial wound debridements. There were 2 patients in study that complained of implant related hardware symptoms, both implants were removed after complete radiological union. One patient in this study had ankle stiffness that was managed with ankle physiotherapy. Complications seen in this study design are shown in Table 2.

Table 1: Various parameters studied.

\begin{tabular}{|lcc|}
\hline Parameters studied & $\begin{array}{l}\text { No. of } \\
\text { patients }\end{array}$ & $\begin{array}{l}\text { Percentage } \\
(\%)\end{array}$ \\
\hline Mode of injury & 16 & 76.2 \\
\hline RTA & 5 & 23.8 \\
\hline Fall & & \\
\hline Fibula status & 18 & 85.7 \\
\hline Fracture & 3 & 14.3 \\
\hline Intact & & \\
\hline AO/OTA type & 5 & 23.8 \\
\hline A0 43A1 & 9 & 42.9 \\
\hline A0 43A2 & 7 & 33.3 \\
\hline A0 43A3 & \\
\hline Delay in surgery (week) & 7 & 33.3 \\
\hline$<1$ & 14 & 66.7 \\
\hline$>1$ & 7 & \\
\hline Functional outcome (OM score) & 33.3 \\
\hline Excellent & 10 \\
\hline Good & 47.7 \\
\hline Fair & 2 & 9.5 \\
\hline Poor & 2 & 9.5 \\
\hline
\end{tabular}

Table 2: Complications encountered.

\begin{tabular}{|lcc|}
\hline Complications & $\begin{array}{c}\text { No. of } \\
\text { patients }\end{array}$ & Percentage \\
\hline Malunion & 2 & 9.5 \\
\hline Varus $>\mathbf{1 5} \mathbf{~ m m ~}$ & & \\
\hline Shortening $>\mathbf{1 ~ c m}$ & & \\
\hline Non-union & 1 & 4.8 \\
\hline Infection & 2 & 9.5 \\
\hline Hardware & 2 & 9.5 \\
\hline Ankle stiffness & 1 & 4.8 \\
\hline
\end{tabular}

Using Olerud and Molander scoring system, 7 patients $(33.3 \%)$ patients had excellent outcome at the end of one year follow up, 10 patients $(47.7 \% \%)$ had good outcome, 2 patients $(9.5 \%)$ had fair outcomes and 2 patients $(9.5 \%)$ had poor outcomes. Average Olerud Molander score achieved was 80 .

\section{DISCUSSION}

Fractures around distal tibia are usually comminuted due to its subcutaneous location. Significant soft tissue damage along with limited vasculature furthers ads to difficulty in treating these fractures. Results of operative treatment are dependent on the severity of the initial injury, the quality 
and stability of the reduction. Immobilization by splinting, icepacks and delaying surgery help in limiting further soft tissue injury and better preoperative soft tissue condition. Borelli et al in his study concluded that open reduction in the distal tibia further ads to vascular insult and delays union. ${ }^{11}$ Anatomical reduction of the fracture before applying the plate is very important surgical step. Gupta et al in his study involving 79 patients reported that suboptimal pre contouring of the plate can result in delayed union, nonunion, prominent hardware, malleolar skin irritation and pain. ${ }^{12}$ In our study design there is a higher incidence of male involvement with male female ratio of 2.5:1 and mean age being 40.7 years. These observations are in agreement with previous studies done by Aggarwal et al and Collinger et al. ${ }^{13,14}$ The most common cause of distal tibia fracture in our study was RTA (76.2\%) followed by fall. Same results have been reciprocated by Soni and Patel in their study. ${ }^{15}$ Most of the patients $(85.7 \%)$ in our study had ipsilateral fibula fracture which is also the result of previous studies done Bonnevialle et al. ${ }^{16}$ In this study most patients $(66.7 \%)$ were operated after the 1st week of admission. Radiological union was achieved within 17.6-24.2 weeks (mean 18.4 weeks). Comparison of union duration with other studies (Table 3).

Table 3: Comparison with previous studies.

\begin{tabular}{|c|c|c|}
\hline Study & Method & $\begin{array}{l}\text { Average fracture } \\
\text { union (weeks) }\end{array}$ \\
\hline Collinger et al ${ }^{14}$ & MIPPO & 21 \\
\hline $\begin{array}{l}\text { Abidmushtaq } \\
\text { et } \mathrm{al}^{25}\end{array}$ & MIPPO & 22 \\
\hline Im et al $^{18}$ & ORIF & 20 \\
\hline Hazrika et al ${ }^{19}$ & MIPPO & 19.3 \\
\hline Present study & MIPPO & 18.4 \\
\hline
\end{tabular}

Acceptable degree of alignment is 5 degree of varus/valgus, 10 degree of recurvatum or procurvatum and $<1 \mathrm{~cm}$ of shortening. Out of 21 patients in study, 18 patients were found to have acceptable reduction and alignment post operatively and at 6 months follow up while there were 2 cases of malunion $(9.5 \%)$ and 1 case (chronic smoker) of non-union $(4.8 \%)$ that was addressed with autologous cancellous bone grafting. Redfern et al had 1 malunion in a series of 20 patients treated with MIPO with DTLCP in their study on minimally invasive plate osteosynthesis in distal tibial fractures. ${ }^{8}$ Helfet et al in their series of 20 patients of distal tibial fractures treated by MIPO reported 4 cases of malunion. ${ }^{20}$ We had 2 patients $(9.5 \%)$ who had superficial wound infections (one among them was diabetic). There was no case of deep infection. Vasantharaman et al also reported $10 \%$ superficial infection in his review of 20 patients with distal tibia fractures managed by plating. ${ }^{21}$ In our study there were just 2 cases of implant related hardware symptoms needing implant removal after radiological union. All patients had good ankle range of motion (equal to opposite ankle) except one patient who developed ankle stiffness which was managed by ankle physiotherapy.
The functional outcome using Olerud and Molander scoring system depicted $81 \%$ good to excellent results. Mean Olerud Molander score was 80 . Also, $19 \%$ cases had fair to poor results (non-union, malunion and stiff ankle) (Table 4).

Table 4: Comparison of functional results with previous studies using OM score.

\begin{tabular}{|c|c|c|c|}
\hline Study & Method & $\begin{array}{l}\text { Accept } \\
\text {-able }\end{array}$ & $\begin{array}{l}\text { Not } \\
\text { acceptable }\end{array}$ \\
\hline Teeny et $\mathrm{al}^{22}$ & ORIF & 50 & 50 \\
\hline Im et $a^{18}$ & ORIF & 88 & 12 \\
\hline Gao et $a^{23}$ & MIPPO & 87 & 13 \\
\hline $\begin{array}{l}\text { Hazarika } \\
\text { et al }{ }^{19}\end{array}$ & MIPPO & 87 & 13 \\
\hline Ozkaya et al ${ }^{24}$ & MIPPO & 81 & 19 \\
\hline Present study & MIPPO & 81 & 19 \\
\hline
\end{tabular}

\section{CONCLUSION}

The treatment of fractures around distal tibia are challenging but not impossible. Careful understanding of fracture anatomy, displacement and soft tissue status is of utmost important before planning surgery. MIPO technique of plating preserves the blood supply to the fracture fragments, doesn't interfere with fracture hematoma and has minimal complications. Clinicradiological and functional results of patients at the end of our follow up were very encouraging and we conclude that MIPO plating of distal tibia fracture has satisfactory results in experienced hands.

\section{Funding: No funding sources \\ Conflict of interest: None declared}

Ethical approval: The study was approved by the institutional ethics committee

\section{REFERENCES}

1. Tornetta P III, Weiner L, Bergman M. Pilon fractures: Treatment with combined internal and external fixation. J Orthop Trauma. 1993;7:489-96.

2. Othman M, Strzelczyk P. Results of conservative treatment of "pilon" fractures. Ortop Traumatol Rehabil. 2003;5:787-94.

3. Digby JM, Holloway GM, Webb JK. A study of function after tibial cast bracing. Injury. 1983;14:432-9.

4. Salton HL, Rush S, Schuberth J. Tibial plafond fractures: Limited incision reduction with percutaneous fixation. J Foot Ankle Surg. 2007;46(4):261-9.

5. Anglen JO. Early outcome of hybrid external fixation for fracture of the distal tibia. J Orthop Trauma. 1999;13:92-7.

6. Paluvadi SV, Lal H, Mittal D. Management of fractures of the distal third tibia by minimally invasive plate osteosynthesis - a prospective series of 50 patients. J Clin Orthop Trauma. 2014;5(3):129-36. 
7. Ronga M, Longo UG, Maffulli N. Minimally invasive locked plating of distal tibia fractures is safe and effective. Clin Orthop Relat Res. 2010;468(4):975-82.

8. Redfern DJ, Syed SU, Davies SJM. Fractures of the distal tibia: minimally invasive plate osteosynthesis. Injury. 2004;35:615-20.

9. Apivatthakakul T, Phornphutkul C, Patumasutra S. Idea and innovation: Simple minimally invasive plate osteosynthesis (MIPO) instruments. Injury Extra. 2009;40:39-44.

10. Vallier HA, Le TT, Bedi A. Radiographic and clinical comparisons of distal tibia shaft fractures (4 to $11 \mathrm{~cm}$ proximal to the plafond): plating versus intramedullary nailing. J Orthop Trauma. 2008;22(5):307-11.

11. Borrelli J, Prickett W, Song E, Becker D, Ricci W. Extraosseous blood supply of the tibia and the effects of different plating techniques: a human cadaveric study. J Orthop Trauma. 2002;16:691-5.

12. Gupta RK, Rohilla RK, Sangwan K, Singh V, Walia S. Locking plate fixation in distal metaphyseal tibial fractures: series of 79 patients. Inter Orthop. 2010;34:1285-90.

13. Agarwal N, Sood A. A study on surgical management of distal tibial fractures by using minimally invasive technique of percutaneous plate osteosynthesis with locking compression plate. Int $\mathbf{J}$ Health Sci Res. 2018;8(10):138-44.

14. Collinger C, Sander R. Minimally - Invasive Plating. J Am Acad Orthop Surg. 2000:8:211-7.

15. Soni K, Patel J. Comparative study of distal tibia fractures managed by nailing vs platin. Nat J Clin Orthopaed. 2018;2(3):106-12.

16. Bonnevialle P, Lafosse JM, Pidhorz L. Distal leg fractures: How critical is the fibular fracture and its fixation? Orthop Traumatol Surg Res. 2010;96(6):2010.

17. Mushtaq A, Shahid R, Asif M. Distal tibia fracture fixation with Locking Compression Plate (LCP) Using minimally Invasive percutaneous osteosynthesis (MIPO) Technique. Eur J Trauma Emerg Surg. 2009;35:159-64.

18. Im GI, Tae SK. Distal metaphyseal fractures of tibia: a prospective randomized trial of closed reduction and intramedullary nail versus open reduction and plate and screws fixation. J Trauma. 2005;59(5)1219-23.

19. Hazarika S, Chakravarthy J, Cooper J. Minimally invasive locking plate osteosynthesis for fractures of the distal tibia- results in 20 patients. Injury. 2006;37(9).

20. Helfet DL, Koval K. Intraarticular pilon fractures of the tibia. Clin Orthop Relat Res. 1994;298:221-8.

21. Vasantharaman R, Devendran R, Ashok L. Outcome Analysis of Distal Tibial Fractures Managed by Open Reduction Internal Fixation using Plate Osteosynthesis. Int J Sci Stud. 2019;7(1):1-4.

22. Teeny SM, Wiss DA. Open reduction and internal fixation of tibial plafond fractures. Variables contributing to poor results and complications. Clin Orthop Relat Res. 1993;(292):108-17.

23. Gao H, Zhang CQ, Luo CF, Zhou ZB, Zeng BF. Fractures of the distal tibia treated with polyaxial locking plating. Clin Orthopaed Relat Res. 2009;467(3):831-7.

24. Ozkaya U, Parmaksizoglu AS, Gul M, Sokucu S, Kabukcuoglu Y. Minimally Invasive Treatment of Distal Tibial Fractures with Locking and NonLocking Plates. Foot Ankle Int. 2009;30(12):1161-7.

25. Mushtaq, A., Shahid, R., Asif, M. et al. Distal Tibial Fracture Fixation with Locking Compression Plate (LCP) Using the Minimally Invasive Percutaneous Osteosynthesis (MIPO) Technique. Eur J Trauma Emerg Surg. 2009;35:159-64.

Cite this article as: Singh $\mathrm{P}$, Ghani A, Singh SP, Singh A. Clinico-radiological and functional outcomes of distal tibia extra-articular fractures (AO 43A1-A3) managed by minimal invasive plate osteosynthesis in a tertiary care hospital: a series of 21 patients. Int J Res Orthop 2021;7:497-501. 